\title{
Health Library Association of British Columbia
}

Members of the Health Library Association of British Columbia (HLABC) have recently started an online journal club. Using web-conferencing technology, the meetings will be held online in order to include as many members as possible. Meetings will ideally be held once a month. Each time a new journal club meeting date is set, an e-mail will be sent out to the HLABC listserv to advertise the event including the citation (preferably with a link to the full text) for the article that will be discussed in the meeting and a link to a critical appraisal tool (e.g., the EBL Critical Appraisal Checklist by Lindsay Glynn: http://www.nihs.ie/pdf/EBL $\% 20$ Critical\%20Appraisal $\% 20$ Checklist.pdf). Preferably, the chosen article will be on a topic of interest to a wide range of health library staff and it will be openly accessible.

All HLABC members have been invited to be involved in the journal club through the membership listserv. An HLABC member will serve as the journal club facilitator for at least one meeting. Ideally, this will be a rotating role among the regular journal club members. Expectations of journal club participants include reading the article before the journal club meets, asking questions, and contributing to discussion. Conversely, the journal club facilitator will be expected to select the article for the journal club meeting, read the article in depth and pre-appraise it, introduce the article at the beginning of the journal club meeting, summarizing it in $10 \mathrm{~min}$ or less, and prepare a few discussion points to lead the discussion. Several members met virtually on 15 April 2011 for the inaugural journal club meeting, where the JCHLA article "The provision of bioinformatics services in Canadian academic libraries" was discussed (see Appendix A for full journal club guidelines).

At the 2010 British Columbia Libraries Association Conference, HLABC members asked British Columbia's public librarians if a portal to consumer health information resources would be useful to them. Since $100 \%$ of the responses indicated a resounding "Yes!', HLABC members recently created an online Portal to Consumer Health Information using the free wiki software, PBWorks. Several HLABC members formed a Consumer Health Interest Group in the fall of 2010 and began work on the portal by pooling their collective resources for answering consumer health reference questions. The portal is now complete, and includes useful links to start a consumer health reference search, different subject categories such as diabetes and women's health, as well as useful supplementary material including tips for evaluating health information on the internet. Wherever possible, a focus was kept on British Columbia-related information. The portal was promoted to public librarians at the 2011 British Columbia Libraries Association Conference during health-related conference sessions and with a bookmark. It is hoped that this portal will nurture a stronger networking and collaborating link between health and public libraries in British Columbia. Check out the portal for yourself at www.hlabcconsumerhealthportal. pbworks.com.

Several months ago the 2010-2011 HLABC Continuing Education \& Programming Director (Ursula Ellis) surveyed members on desired topics and locations for Continuing Education events, and many of these suggestions have been presented and discussed already. Recent and upcoming topics include Canadian copyright law, social media and health libraries, health research updates, and the use of screencasting software for library instruction.

\author{
Brooke Ballantyne Scott \\ Librarian \\ Royal Columbian Hospital \\ 330 East Columbia Street \\ New Westminster, BC V3L 3 W7, Canada \\ E-mail: brooke.scott@fraserhealth.ca
}




\section{Appendix A}

\section{Health Libraries Association of British Columbia journal club guidelines}

\section{Membership}

Any Health Libraries Association of British Columbia (HLABC) member can be involved in the journal club. An HLABC member will also serve as the journal club facilitator for at least one meeting. Ideally, this should be a rotating role among the regular journal club members.

\section{Meeting Format}

The preferred time and day of the week for journal club meetings has been established as one hour at noon on Fridays. The meetings will be held online using web-conferencing technology.

Ideally, meetings will be held once a month. Each time a new journal club meeting date is set, an e-mail will be sent out to the HLABC listserv to advertise the event.

This e-mail will include:

- The date and time of the journal club meeting

- The name and contact information of the facilitator for the journal club meeting

- The citation (preferably with a link to the full text) for the article that will be covered in the journal club meeting

- The link to a critical appraisal tool (e.g., the EBL Critical Appraisal Checklist by Lindsay Glynn: http://www.nihs.ie/pdf/ EBL $\% 20$ Critical $\% 20$ Appraisal\%20Checklist.pdf).

Preferably, this article will be on a topic of interest to a wide range of health library staff, and the article will be openly accessible. Interested members will then e-mail the group facilitator for that meeting to indicate their intention to participate.

\section{Expectations for journal club participants}

There are four main expectations for journal club participants:

1. Read the article before the journal club meets

2. Don't worry about your ignorance on a certain topic - sometimes this is the key to creative discussions!

3. Ask questions

4. Contribute to discussions

Critical appraisal tools or checklists may be used by journal club participants to guide their reading of the article. Journal club participants may also consider some of the following questions to guide their reading of the article:

- What are the implications for medical library practice in general?

- Should current practice be changed based on this article?

- What is the applicability to my individual medical library practice?

- Is there fault in the logic used by the authors?

- Can the presented data be interpreted differently?

\section{Expectations for the journal club facilitator}

There are four main expectations for the journal club facilitator:

1. Select an article to be discussed at the journal club meeting

2. Read the article in depth and pre-appraise it

3 Introduce the article at the beginning of the journal club meeting, summarizing it in 10 minutes or less

4. Prepare a few discussion points, and use the rest of the time to lead the discussion 